\title{
The rationale and design of
} TransCon Growth Hormone for the

\section{treatment of growth hormone deficiency}

\author{
Kennett Sprogøe', Eva Mortensen², David B Karpf ${ }^{2}$ and Jonathan A Leff ${ }^{2}$ \\ ${ }^{1}$ Ascendis Pharma A/S, Hellerup, Denmark \\ ${ }^{2}$ Ascendis Pharma, Inc., Palo Alto, California, USA
}

Correspondence

should be addressed

to K Sprogøe

Email

ks@ascendispharma.com

\begin{abstract}
The fundamental challenge of developing a long-acting growth hormone (LAGH) is to create a more convenient growth hormone $(\mathrm{GH})$ dosing profile while retaining the excellent safety, efficacy and tolerability of daily $\mathrm{GH}$. With $\mathrm{GH}$ receptors on virtually all cells, replacement therapy should achieve the same tissue distribution and effects of daily (and endogenous) GH while maintaining levels of GH and resulting IGF-1 within the physiologic range. To date, only two LAGHs have gained the approval of either the Food and Drug Administration (FDA) or the European Medicines Agency (EMA); both released unmodified $\mathrm{GH}$, thus presumably replicating distribution and pharmacological actions of daily GH. Other technologies have been applied to create LAGHs, including modifying GH (for example, protein enlargement or albumin binding) such that the resulting analogues possess a longer half-life. Based on these approaches, nearly 20 LAGHs have reached various stages of clinical development. Although most have failed, lessons learned have guided the development of a novel LAGH. TransCon GH is a LAGH prodrug in which $\mathrm{GH}$ is transiently bound to an inert methoxy polyethylene glycol (mPEG) carrier. It was designed to achieve the same safety, efficacy and tolerability as daily GH but with more convenient weekly dosing. In phase 2 trials of children and adults with growth hormone deficiency (GHD), similar safety, efficacy and tolerability to daily GH was shown as well as GH and IGF-1 levels within the physiologic range. These promising results support further development of TransCon GH.
\end{abstract}

\author{
Key Words \\ - long-acting growth \\ hormone
}

- TransCon GH

\section{Introduction}

Following secretion from the anterior pituitary, human growth hormone $(\mathrm{GH})$ is transported throughout the body, exerting its effects via GH receptors on virtually every cell of the body. In addition to muscle and bone growth, GH is critical for a wide variety of bodily functions, including adiposity regulation, glucose control, lipid metabolism, and cognition $(1,2,3)$. These effects are mediated both directly by GH and indirectly by insulin-like growth factor (IGF-1). In target organs (e.g., liver) and peripheral tissue (e.g., growth plate), GH induces production of IGF-1. The liver is the primary source of circulating IGF-1, which regulates endogenous $\mathrm{GH}$ production via a negative feedback loop, while tissue-derived IGF-1 acts in both an autocrine and paracrine fashion (4). GH and IGF-1 thus work in concert, with IGF-1 augmenting the anabolic actions of $\mathrm{GH}$ while opposing the hyperglycemic and lipolytic effects of GH (5). http://www.endocrineconnections.org
DOI: $10.1530 /$ EC-17-0203
() 2017 The authors Published by Bioscientifica Ltd

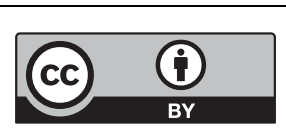

This work is licensed under a Creative Commons Attribution 4.0 International License. 
Growth hormone deficiency (GHD), which may be congenital or acquired, can afflict any age and manifests itself similarly across age ranges. Children with GHD suffer from short stature, increased and disproportionately distributed body fat, lipid abnormalities and decreased bone mineral density while adults with GHD suffer similar consequences except short stature $(6,7)$.

Because of the ubiquity of $\mathrm{GH}$ receptors, it is important that a GHD therapeutic be small enough to permeate all tissues and carry out all the beneficial effects of GH. GHD is treated with replacement therapy, i.e., recombinant daily human GH (somatropin, molecular weight $22 \mathrm{kDa}$ ). Demonstrated to be safe and effective, somatropin is administered subcutaneously (SC) on a daily basis. This is particularly burdensome given that patients with GHD usually require ongoing treatment for many years resulting in thousands of injections. Understandably, many patients are, or eventually become, noncompliant, leading to suboptimal outcomes $(8,9,10,11,12,13)$.

Studies of GH infusion have demonstrated that continuous exposure to unmodified $\mathrm{GH}$ is a safe and effective alternative to daily injections $(14,15,16)$. Thus, to ameliorate injection fatigue and improve outcomes, development of long-acting formulations has garnered considerable interest. As early as 1979, Lippe and coworkers evaluated the efficacy of a depot $\mathrm{GH}$ preparation in GHD children (17). Since then, multiple companies have attempted to develop a long-acting growth hormone (LAGH).

In 2015, the Growth Hormone Research Society convened a workshop to discuss LAGH development. The group theorized that by decreasing injection frequency, LAGH would improve adherence and therefore outcomes. A number of potential safety issues related to LAGH were identified, including (i) supraphysiological elevations of GH and/or IGF-1, (ii) trough GH concentrations above normal physiological levels, (iii) fluctuating IGF-1 levels, (iv) elevated IGF-1 in the absence of GH bioactivity, (v) nonphysiological tissue distribution due to distinct biological features of the products and (vi) the specific chemical composition of each LAGH product (11).

To date, nearly 20 LAGHs have reached various stages of development (Table 1). Most have failed, some were successfully launched but failed to gain commercial success, two are currently only available in narrow geographic regions, while the remaining are in various stages of clinical development (11). With the goal of satisfying an unmet need, work to develop a safe and effective LAGH continues.

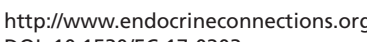

\section{True replacement therapy with convenient dosing}

The fundamental challenge of developing a LAGH is to create a more convenient $\mathrm{GH}$ dosing profile while retaining the excellent safety, efficacy and tolerability profile of daily GH. With GH receptors in essentially all tissues, replacement therapy should achieve the same tissue distribution and effects of endogenous (and daily) GH while maintaining levels of GH and resulting IGF-1 within the physiologic range.

To create a LAGH that extends the GH half-life thereby allowing less frequent dosing, two basic approaches have been followed: (a) combine unmodified GH with a prolongation technology (a depot, crystal or prodrug) or (b) modify GH in such a way (protein enlargement or albumin binding) that the GH analogue has a longer half-life.

\section{Formulations based on unmodified GH}

Only LAGHs based on unmodified GH have ever gained approval in Europe or the United States. Nutropin Depot is the only LAGH ever approved by the Food and Drug Administration (FDA). It consists of recombinant human GH encapsulated in biodegradable polylactide-coglycolic acid (PLGA) polymer microspheres. Unmodified GH was released slowly from the microsphere into SC tissue (18). Nutropin Depot only achieved an annualized height velocity $(\mathrm{HV})$ of $8.2 \mathrm{~cm} /$ year that, according to a letter issued by the FDA, was not comparable to daily GH (19). The low growth rates observed with Nutropin Depot may have been related to lower GH exposure (due to suboptimal pharmacokinetics; PK) compared to daily injections using standard doses of $0.30 \mathrm{mg} / \mathrm{kg} / \mathrm{wk}(20,21)$. In addition to subpar efficacy, the Nutropin Depot formulation also required multiple injections in patients weighing more than $26 \mathrm{~kg}$. Large injection volumes along with injection site reactions rendered the product poorly tolerated (18, $20)$, and it was eventually withdrawn from the market $(11,13)$.

LB03002 consists of unmodified GH embedded in sodium hyaluronate microparticles suspended in triglycerides and provided equivalent efficacy to that of daily GH (Genotropin) both in terms of annualized HV in children as well as decreased fat mass in adults $(22,23$, 24). However, in children receiving LB03002, non-serious injection site reactions and non-neutralizing anti-GH antibodies were observed, the latter with an incidence 5 times higher than daily $\mathrm{GH}$, although without impact on safety. Neutralizing antibodies were not detected

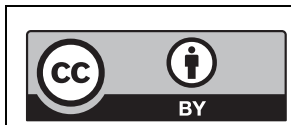

This work is licensed under a Creative Commons Attribution 4.0 International License. 
Table 1 A summary of long-acting growth hormones categorized by development approach.

\begin{tabular}{l} 
Approach \\
\hline Unmodified GH \\
- Half-life extension \\
achieved by the \\
slow-release of \\
somatropin from \\
polymeric depot, \\
crystal, or prodrug
\end{tabular}

size (except

is modified with a tag)

Company
Genentech, Inc.
LG Life Sciences, Ltd.

Product

Nutropin Depot

GH encapsulated in polylactidecoglycolic acid microparticles

LB03002

$\mathrm{GH}$ encapsulated in sodium hyaluronate microparticles

Altus Pharmaceuticals, Inc. ALTU-238

GH crystallization

TransCon GH Transiently PEGylated GH prodrug

\begin{tabular}{lll}
\hline $\begin{array}{l}\text { Modified GH - Half-life } \\
\text { achieved by }\end{array}$ & GeneScience & Jintrolong \\
Pharmaceuticals Co., Ltd. & Permanently PEGylated GH
\end{tabular}

increasing molecular Pfizer, Inc.

NNC0195-0092, which Novo Nordisk A/S

small albumin affinity Ambrx, Inc.

Teva Pharmaceutical
Industries, Ltd.
Versartis, Inc.
OPKO Health, Inc.
Novo Nordisk A/S
Genexine, Inc., and
Handok, Inc.
Hanmi Pharmaceutical
Co., Ltd.

PHA-794428

Permanently PEGylated GH

NNCl126-0083

Permanently PEGylated GH

ARX201

Permanently PEGylated and mutated GH

TV-1106

GH fused to albumin

VRS-317

GH fused to half-life extension

technology polypeptides

MOD-4023

GH fused to carboxyterminal peptides

NNC0195-0092

Mutated GH attached to an albumin

affinity tag

GX-H9

GH fused to an Fc fragment

LAPS-rhGH/HM10560A

$\mathrm{GH}$ fused to an Fc fragment
Pediatric GHD development status

Approved in the U.S; later

withdrawn

Approved but not marketed in

Europe; available in South Korea

Discontinued

Phase 3

Available in China

Discontinued

Discontinued

Discontinued

Discontinued

Phase 3

Phase 3

Phase 2

Phase 2

Phase 2 except in one patient with a GH gene deletion (25). In its assessment report, the European Medicines Agency (EMA) highlighted that GH (and resulting IGF-1) should not exceed physiological levels when used as substitution therapy based on the concern that anabolic compounds may promote tumor proliferation (25). It concluded that GH and IGF-1 exposure induced by LB03002 were similar to daily GH. This product was approved by the EMA but not marketed in the European Union; it is available in South Korea.

\section{Formulations based on modified GH}

Protein enlargement technologies have been used to prolong the half-life of GH by permanently increasing molecular size. This can be achieved by attaching one or more synthetic peptides or other polymers such as polyethylene glycol (PEG) or by fusion of GH with other proteins such as albumin, non-naturally occurring repeat amino acid sequences (e.g., XTEN), carboxyterminal peptide (CTP) or Fc antibody fragments. These increases in molecular size reduce renal filtration and interactions with the GH receptor (reducing receptor-mediated degradation), thus prolonging half-life.

Permanent PEGylation, the covalent binding of one or more PEG molecules to an active drug, is a technology frequently used to extend the half-life and improve other pharmacological properties of proteins and peptides. At least a dozen PEGylated biopharmaceuticals have been approved in the United States and Europe (26). In addition, PEG has found widespread use in the industrial, cosmetic and food industries.

Creating a LAGH by permanent PEGylation has been attempted repeatedly and led to one approval in China (11). Other programs have failed at various stages of clinical development. Altered pharmacology of the protein-enlarged GH has led to unexpected outcomes, for example, injection site lipoatrophy in patients administered permanently PEGylated GH, PHA-794428; a higher incidence was observed among females, and http://www.endocrineconnections.org DOI: 10.1530/EC-17-0203
○ 2017 The authors Published by Bioscientifica Ltd
This work is licensed under a Creative Commons Attribution 4.0 International License. 
the incidence increased with repeat injections (27), suggesting a change in adipocyte susceptibility to the lipolytic activity of the protein-enlarged GH over time. The findings of lipoatrophy led Pfizer, Inc., to discontinue development of PHA-794428 (28).

Novo Nordisk A/S developed another PEGylated LAGH, NNC126-0083, which showed potentially acceptable PK and pharmacodynamic (PD) profiles in adults with GHD following once-weekly administration (29). However, a satisfactory IGF-1 profile was not achieved in children with GHD (30), and as a result, development was discontinued $(31,32)$.

While PEG remains the best characterized inert polymer for modifying biopharmaceuticals and has demonstrated safety and tolerability in chronic settings, repeat parenteral administration of PEGylated proteins to animals has in some cases been associated with vacuolation - the formation of enclosed intracellular compartments for clearance of debris - in macrophages and/or histiocytes of various organs, including renal tubular cells (33). Formation of vacuoles in the choroid plexus of cynomolgus monkeys have been reported for a permanently PEGylated GH analogue, ARX201, which was being developed by Ambrx (34). Vacuolation, which occurs mainly in phagocytes, has not been linked to organ dysfunction in toxicology studies, and the body of evidence for approved PEGylated biopharmaceuticals has not identified any clinical consequences for compounds where vacuolation was observed in toxicology studies (35).

Active transport (movement of molecules across cell membranes) by receptors may be a determining factor as to which drugs cause vacuolation and which do not. Based on repeat-dose toxicity studies of a permanently PEGylated GH formulation administered SC to cynomolgus monkeys, vacuolation has been observed within cells with GH receptors, specifically choroid plexus ependymal cells. When the unconjugated PEG molecule itself (i.e., free PEG without GH attached) was administered, a 10-fold higher dose was required to detect it within ependymal cells. In other words, permanently PEGylated GH is taken up into ependymal cells much more readily than unconjugated PEG. This is likely a result of receptor-mediated transport of GH in which PEG uptake is an incidental consequence compared to nonspecific cellular uptake (pinocytosis) of PEG alone (36).

A review of published data and information provided by a survey conducted by BioSafe (a committee within $\mathrm{BIO}$, the Biotechnology Industry Organization) stated that the body of evidence available for approved PEGylated biopharmaceuticals has not identified any clinically reported functional consequences for compounds where vacuolation was observed in toxicology studies (35).

TV-1106 is a long-acting GH developed by Teva Pharmaceutical Industries, Ltd. TV-1106 comprises human serum albumin (HSA) genetically fused to the N-terminus of GH. Despite both GH and albumin being naturally occurring, the fusion protein had a high immunogenic potential leading to neutralizing antibodies in 4 of 48 (8.3\%) TV-1106-treated subjects in a phase 2 trial of children with GHD. When Teva Pharmaceutical Industries, Ltd., reassessed the benefit/risk balance of TV-1106 and the likelihood of regulatory success, the trial and product development were terminated (37).

Somavaratan (VRS-317) is a fusion protein with a molecular weight of $119 \mathrm{kDa}$ being developed by Versartis, Inc., for twice monthly injections. The $22 \mathrm{kDa} G H$ domain is enlarged by two chains of hydrophilic, non-naturally occurring amino acid sequences (XTEN) added to the $\mathrm{N}$ - and C-termini of $\mathrm{GH}$. This enlargement prolongs the half-life of $\mathrm{GH}$ by increasing its hydrodynamic size and decreasing receptor-mediated clearance through a reduction in receptor binding (38). Somavaratan is currently in phase 3 clinical development. Adverse events following somavaratan administration were reported to be similar to daily $\mathrm{GH}$ in a phase 2 trial of children with GHD. However, the trial did not include an active comparator (38). Depending on the somavaratan dose, annualized HV was reported to be $7.58-8.61 \mathrm{~cm} /$ year (38). However, neutralizing antibodies have been reported for 2 of 64 (3\%) subjects administered somavaratan in the phase 2 trial of children with GHD $(39,40)$. The incidence of non-neutralizing anti-GH antibodies has not been reported.

Developed by OPKO Health Inc., MOD-4023 is a once-weekly administered GH fusion protein consisting of three carboxyterminal peptide (CTP) copies of the beta chain of human chorionic gonadotropin. MOD-4023 has demonstrated growth similar to daily GH in a phase 2 trial of children with GHD with a phase 3 trial recently initiated (41). However, a recent phase 3 trial in adults with GHD missed its primary endpoint of truncal fat mass reduction; with only a $0.4 \mathrm{~kg}$ weight decrease in the active arm, a statistical difference from placebo was not observed $(42,43)$.

A different human $\mathrm{GH}$ derivative was formulated by Novo Nordisk A/S in which a side chain with a terminal fatty acid (with noncovalent albumin-binding properties) is attached to a single point mutation in the $\mathrm{GH}$ backbone, thus decreasing clearance and increasing half-life (44). Somapacitan (NNC0195-0092) binds tightly,

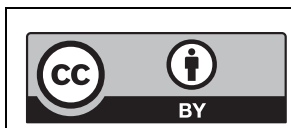

This work is licensed under a Creative Commons Attribution 4.0 International License. 
but reversibly, to human albumin, leaving an estimated $0.04 \%$ of somapacitan unbound (45). Phase 3 data in adults with GHD have demonstrated that once-weekly somapacitan was more convenient than daily GH (46), supporting the idea that LAGH may improve compliance. Somapacitan is currently in phase 3 development for adults with GHD and in phase 2 development for pediatric GHD.

Co-developed by Handok, Inc., and Genexine, Inc., GX-H9 is a recombinant human GH in which GH is fused to an Fc antibody fragment (hybrid Fc) to extend half-life. A phase 2 trial in children with GHD is ongoing (47).

LAGH development based on GH modification by molecular enlargement and albumin binding creates new active GH analogues. These analogues are designed to support dosing frequencies from 1 to 2 weeks and up to 1 month. As such, upon injection, these $\mathrm{GH}$ analogues are absorbed into the bloodstream, leading to supraphysiological GH activity (at maximum analogue concentrations shortly after administration) greatly exceeding that obtained with daily GH administration. With time, concentration of the modified GH analogue falls until subsequent dosing, again leading to GH activity levels above the normal range. Supraphysiologic GH may be associated with increased cardiac output, concentric left ventricular remodeling, cardiomyopathy and acromegalic symptoms $(48,49,50,51,52)$. Clinical manifestations of $\mathrm{GH}$ hypersecretion evolve slowly and can take years to diagnose (52), a noteworthy consideration when developing a LAGH. Given the potential for adverse effects secondary to supraphysiologic $\mathrm{GH}$, regulators and others have expressed concerns $(11,25)$.

Permanently enlarging GH may compromise tissue distribution. To assess the effect of molecular size on tibial growth plate penetration, Farnum and coworkers used a murine model and demonstrated that $40 \mathrm{kDa}$ and larger dextrans do not enter or diffuse through the growth plate (53). Similarly, Gill and coworkers showed an inverse relationship between the molecular size of therapeutic proteins and extravascular tissue distribution in a human whole-body, physiologically based PK model (54). Additionally, in patients with hepatitis C treated with PEGylated interferons, Caliceti and coworkers found that molecular weight affected relapse rates; PEGylated interferons with higher molecular weight (and therefore lower volumes of distribution) led to higher relapse rates due to the lower chance of infiltrating extravascular tissue (55).

Interestingly, from fish to humans, $\mathrm{GH}$ is highly conserved across species, ranging from 19.4 to $22 \mathrm{kDa}$ in size (56). This suggests evolutionary constraints on the functional GH molecule and the importance of size in maintaining natural tissue penetrance. Unmodified $\mathrm{GH}$ may distribute more fully into peripheral tissues, whereas protein-enlarged $\mathrm{GH}$ molecules may have restricted access. Like unmodified $\mathrm{GH}$, however, protein-enlarged $\mathrm{GH}$ molecules do readily access hepatic GH receptors via fenestrated (open) hepatic sinusoidal endothelium, stimulating hepatic IGF-1 production. Such imbalances within peripheral tissue vs organ distribution have been described for another protein-enlarged hormone, namely permanently PEGylated insulin, in which increased molecular size favored the liver over peripheral tissue (57).

The GH-IGF system has evolved to provide a distinct advantage to the organism, with IGF-1 augmenting the growth-promoting actions of $\mathrm{GH}$ while countering its potentially deleterious effects of hyperglycemia and lipid store depletion (5); the anabolic actions of IGF-1 are synergistic to those of $\mathrm{GH}$, whereas its metabolic actions are antagonistic. When this balance is disrupted, for example, by the administration of certain drugs, the effects of either GH or IGF-1 may predominate, with altered tissue ratios possibly leading to suboptimal therapeutic outcomes.

$\mathrm{GH}$ has direct in vivo effects (independent of circulating IGF-1) exerted, in part, through local IGF-1 production (5). As much as $20 \%$ of linear growth is estimated to be the result of the direct effects of $\mathrm{GH}$ on growing bone $(5,58,59)$, a finding described in animal studies and supported by studies of children with $\mathrm{GH}$ receptor insensitivity/deficiency. Patients with Laron syndrome treated with IGF-1 demonstrated lower growth rates compared to patients with GHD treated with daily $\mathrm{GH}$, supporting the contribution to growth that both GH and IGF-1 provide $(59,60)$.

Tissue balance of GH and IGF-1 is important and disruption may lead to undesired effects. For example, a dearth of lipolytic GH in the presence of lipogenic IGF-1 in fat tissue leads to lipogenesis. While chronic administration of $\mathrm{GH}$ has been shown to reduce fat mass by approximately 15\% (61), unopposed IGF-1 action may lead to accumulation of fat and increases in body mass index $(38,62)$. Studies of patients with Laron syndrome demonstrate this phenomenon; long-term treatment with recombinant IGF-1 is associated with an increase in adiposity (63).

Lipoatrophy, a potentially disfiguring condition that has caused the discontinuation of at least one LAGH (28), is frequently reported among patients administered enlarged GH proteins $(27,64,65,66)$. By contrast, http://www.endocrineconnections.org DOI: 10.1530/EC-17-0203 (c) 2017 The authors Published by Bioscientifica Ltd
This work is licensed under a Creative Commons Attribution 4.0 International License. 
it is thought that unmodified GH carries a lower risk; lipoatrophy is not considered a problem for daily GH. Although the pathogenesis remains unclear (67), high localized concentrations of lipolytic GH in SC tissue may be a contributing factor. Lipoatrophy seems to be more frequent among females possibly because of SC adipose tissue differences between genders (27), making it critically important that studies evaluating safety and tolerability of LAGHs include women.

\section{Integrating previous programs - a target product profile}

Lessons learned from past development attempts have shown that the optimal LAGH must mimic all aspects of daily GH in terms of safety, efficacy and tolerability. These include increased bone growth and mineral deposition, muscle mass gain with improved exercise tolerance and enhanced lipolysis with body composition optimization, and yet, without increased immunogenicity, metabolic complications, injection site reactions, lipoatrophy or pain. Through decades of re-formulation and refinement, daily $\mathrm{GH}$ is available as a single, low volume, stable at room temperature injection administered via easy-to-use pens with fine gauge needles to minimize discomfort. These are administration characteristics that a LAGH must also satisfy.

The only LAGHs that have succeeded in providing both accelerated HV as well as correcting increased truncal adiposity - a measure of GH's effect on metabolism - have been depot formulations, which release unmodified GH. Given GH receptor distribution throughout the body and the pleiotropic actions of GH, a viable LAGH would likely have to maintain the same organ and tissue distribution as native GH, e.g., a candidate based on unmodified GH.

\section{TransCon GH}

\section{Background}

Integrating the experiences of previous developments in the LAGH space, TransCon GH was developed as a sustained-release $\mathrm{GH}$ prodrug. It leverages the known pharmacology and distribution of unmodified $\mathrm{GH}$ in currently available, daily administered products with the properties of an inert PEG-containing carrier molecule. Recombinant human GH is transiently bound to methoxy polyethylene glycol (mPEG) via a proprietary TransCon linker. In contrast to permanent PEGylation, in which the PEGylated construct is the active entity, the TransCon carrier is optimized to inactivate the biological activity (i.e., receptor binding) of $\mathrm{GH}$ within the TransCon GH prodrug complex. This is done by applying a TransCon polymer carrier based on a four-arm structure where the branching points of the four arms are placed close to the protein surface. The mPEG acts as a carrier, inactivating $\mathrm{GH}$, thereby creating a circulating $\mathrm{GH}$ prodrug with an extended circulation time in the body through reduced receptor-mediated elimination and renal excretion.

Based on physiologic $\mathrm{pH}$ and temperature, the TransCon linker autohydrolyzes following first-order kinetics, releasing fully active, unmodified GH over a one-week period designed to allow the same tissue distribution and receptor activation as endogenous GH (Fig. 1). The release of GH liberates the inactive carrier, allowing elimination from the body. PEG is cleared primarily by renal filtration and to a minor extent by hepatobilary excretion (68).

\section{Development}

No adverse effects related to the MPEG carrier have been observed in extensive TransCon GH toxicology studies or clinical trials.

In a phase 2 trial of children with GHD, TransCon GH $(0.21 \mathrm{mg} / \mathrm{kg} /$ week) demonstrated that serum $\mathrm{GH}$, as measured by the maximum $\mathrm{GH}$ concentration $\left(C_{\max }\right)$ and area under the curve (AUC) over 7 days was within the physiological range and similar to a weekly cumulative dose of daily $\mathrm{GH}$ (Genotropin $0.21 \mathrm{mg} / \mathrm{kg} /$ week). IGF-1 changes demonstrated a dose-response relationship to TransCon GH while IGF-1 standard deviation score of all three TransCon GH doses normalized. Mean annualized $\mathrm{HV}$ ranged from $11.9 \mathrm{~cm}$ to $13.9 \mathrm{~cm} /$ year at a dose range of $0.14-0.30 \mathrm{mg} \mathrm{GH} / \mathrm{kg} /$ week and compared favorably to $11.6 \mathrm{~cm} /$ year for $0.21 \mathrm{mg} \mathrm{GH} / \mathrm{kg} /$ week of daily GH (Fig. 2) (69).

Adverse events were mild to moderate and most were unrelated to or unlikely to be related to the study drug. TransCon GH injection site reactions were similar to daily GH without lipoatrophy or nodule formation. One TransCon GH subject developed a low-titer, nonneutralizing antibody response; no neutralizing anti-GH binding antibodies were detected. Similar to daily GH, the mean body mass index SDS was stable across three TransCon GH cohorts (69).

In a phase 2 trial of adults with GHD, TransCon GH demonstrated a linear, dose-dependent increase in $\mathrm{GH}$ peak exposure without accumulation and a similar $C_{\max }$ as compared to daily GH (Omnitrope) at equivalent weekly dosing. IGF-1 exposure following equivalent dosing of

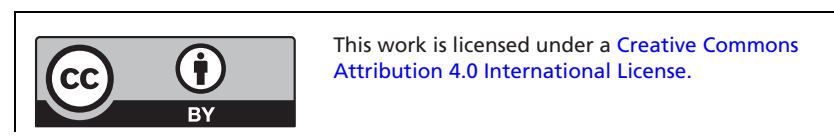



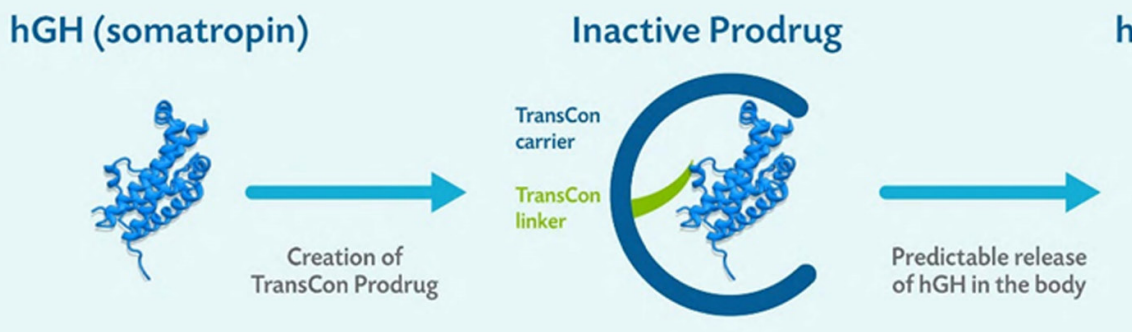

hGH (somatropin) of $\mathrm{hGH}$ in the body

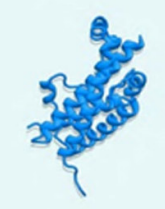

\section{Figure 1}

TransCon GH is a sustained-release inactive prodrug consisting of parent drug, unmodified GH, transiently bound to a carrier, mPEG (40 kDa), via a proprietary TransCon linker that is autohydrolyzed under physiologic $\mathrm{pH}$ and temperature. Reproduced under the terms of the original CCBY licence, from Chatelain P, Malievskiy O, Radziuk K, Senatorova G, Abdou MO, Vlachopapadopoulou E, Skorodok Y, Peterkova V, Leff JA, Beckert M, et al. A randomized phase 2 study of long-acting TransCon GH vs daily GH in childhood GH deficiency, Journal of Clinical Endocrinology and Metabolism, 2017, volume 102, pages 1673-1682, (doi:10.1210/jc.2016-3776).

TransCon GH and Omnitrope was also similar. Overall, TransCon GH was well tolerated. No lipoatrophy or nodule formation occurred at injection sites. No treatmentemergent anti-GH antibodies were detected (70).

Both the pediatric and adult GHD phase 2 results supported advancement of TransCon GH into phase 3 development.

\section{Discussion}

TransCon GH was designed by integrating decades of learning to create a molecule with a once-weekly dosing profile that could match the safety and efficacy of daily GH. The objective was to provide more convenient drug administration to ease the lives of patients with GHD, thereby potentially improving compliance and treatment outcomes.

The Growth Hormone Research Society recently identified a number of potential safety issues relating to the development of LAGH (11). TransCon GH was designed to address these issues by predictably releasing unmodified GH, thereby maintaining the same mode of action and distribution as daily GH while optimizing PK. In phase 2 trials, TransCon $\mathrm{GH}$ produced peak GH levels similar to daily $\mathrm{GH}$, and trough levels returned to baseline before subsequent dosing. In addition, as unmodified GH is released from the prodrug, similar efficacy is achieved on a molar basis compared to daily $\mathrm{GH}$, enabling milligram to milligram conversion. Physiologic levels of GH, in turn, produced physiologic IGF-1 levels in a dose-proportional manner, with IGF-1 levels maintained within the normal range throughout the week (69).

TransCon GH was designed as a prodrug, with $\mathrm{GH}$ transiently bound to the inert $\mathrm{MPEG}$ carrier, which inactivates the $\mathrm{GH}$ molecule, preventing receptor-mediated binding and uptake by $\mathrm{GH}$ receptor-expressing tissues as well as renal clearance. With autohydrolysis of the TransCon linker, unmodified GH is gradually released, designed to maintain similar GH exposure levels and volume of distribution to those obtained with daily $\mathrm{GH}$ administration. Meanwhile, the mPEG carrier-linker complex, still bound together, is excreted separately.

While GHD patients generally do not develop neutralizing antibodies to daily $\mathrm{GH}$, permanent $\mathrm{GH}$ modification creates a non-naturally occurring protein, increasing the risk of inducing anti-GH antibodies that may render GH therapy ineffective. Should this occur, patients may be in a situation similar to children with GH gene deletions who develop neutralizing antibodies to GH therapy and thus require daily IGF-1 administration to maintain growth. Since IGF-1 given alone lacks the direct $\mathrm{GH}$ effect on bone, it produces a lower annualized $\mathrm{HV}$ than daily GH and may increase adiposity due to

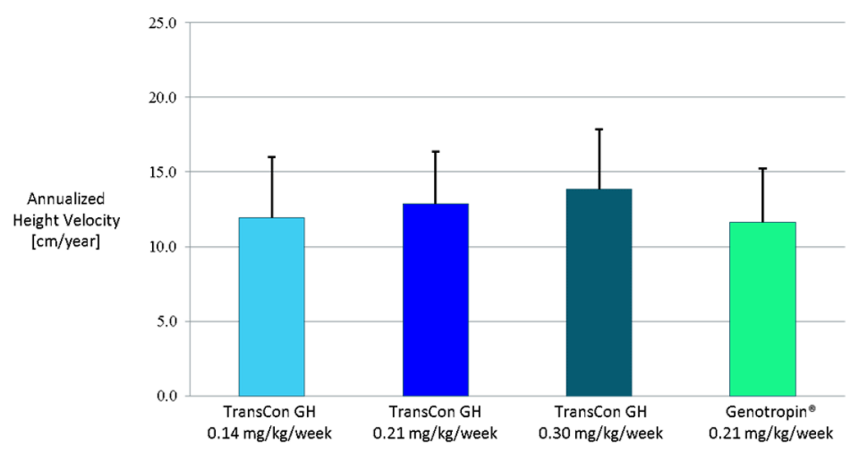

Figure 2

Annualized height velocity (mean +s.D.) in 53 subjects after 26 weeks of TransCon GH vs daily GH (Genotropin) treatment. Reproduced under the terms of the original CCBY licence, from Chatelain $\mathrm{P}$, Malievskiy $\mathrm{O}$,

Radziuk K, Senatorova G, Abdou MO, Vlachopapadopoulou E, Skorodok Y, Peterkova V, Leff JA, Beckert $M$, et al. A randomized phase 2 study of long-acting TransCon GH vs daily GH in childhood GH deficiency, Journal of Clinical Endocrinology and Metabolism, 2017, volume 102, pages 1673-1682, (doi:10.1210/jc.2016-3776). http://www.endocrineconnections.org DOI: 10.1530/EC-17-0203
() 2017 The authors Published by Bioscientifica Ltd
This work is licensed under a Creative Commons Attribution 4.0 International License. 
unopposed IGF-1-mediated lipogenesis (4). In contrast, to date, TransCon GH has shown a lack of immunogenic potential similar to daily $\mathrm{GH}$ in phase 2 studies of both children and adults with GHD. Only one subject developed a low non-neutralizing anti-GH antibody titer that did not appear to affect PK or PD; the subject had an annualized HV of $19.0 \mathrm{~cm} /$ year (69).

While lipoatrophy in adults with GHD has been reported for several protein-enlarged LAGHs, GH activity of TransCon GH is masked upon SC injection. Upon absorption from the injection site, it acts as a circulating depot in the bloodstream, releasing unmodified GH over one week. Thus, local exposure at the injection site is minimized, reducing the risk of lipoatrophy. As expected, no lipoatrophy has been observed in children or adults with GHD to date.

Generally, $0.24 \mathrm{mg} \mathrm{GH} / \mathrm{kg} /$ week of daily $\mathrm{GH}$ is used as a comparator in pediatric LAGH pivotal trials to reflect a globally accepted dose. However, to optimize outcomes, higher daily GH doses of approximately $0.30 \mathrm{mg} / \mathrm{kg} /$ week are commonly used in the United States. As such, a successful LAGH should demonstrate non-inferiority not only to the dose of daily GH used as an active comparator in pivotal trials but also those used in local practices. TransCon GH demonstrated an annualized 6-month HV that was similar to daily GH at doses commonly utilized in the United States, Europe and Japan (i.e., 0.14-0.30 mg GH/kg/week). This efficacy is by design; the small $22 \mathrm{kDa}$ size of unmodified GH released from TransCon GH is, like daily $\mathrm{GH}$, able to reach target tissue such as growth plates. Longterm safety and efficacy will be confirmed in an ongoing phase 3 trial in children with GHD.

\section{Conclusion}

The ultimate goal of LAGH development is to optimize adherence to GH replacement therapy and thus improve patient outcomes in real world conditions. Except for administration frequency, all characteristics of daily $\mathrm{GH}$ must therefore be maintained, including safety, efficacy and tolerability, including lack of immunogenicity. A data review for both failed LAGHs and those currently in development reveals that a product delivering unmodified GH superimposed on an inert prolongation technology may be an appropriate design for a successful LAGH.

\section{Declaration of interest}

K S is an employee of Ascendis Pharma A/S. E M, D K and J A L are employees of Ascendis Pharma, Inc.

\section{Funding}

This work was supported by Ascendis Pharma A/S.

\section{Acknowledgments}

The authors thank the subjects and their caregivers who have participated in the TransCon $\mathrm{GH}$ trials as well as the many individuals who have contributed to the development of TransCon GH.

\section{References}

1 Hazem A, Elamin MB, Bancos I, Malaga G, Prutsky G, Domecq JP, Elraiyah TA, Abu Elnour NO, Prevost Y, Almandoz JP, et al. Body composition and quality of life in adults treated with $\mathrm{GH}$ therapy: a systematic review and meta-analysis. European Journal of Endocrinology 2012166 13-20. (doi:10.1530/EJE-11-0558)

2 Canadian Agency for Drugs and Technologies in Health. Human growth hormone treatment for adult growth hormone deficiency: a review of the clinical effectiveness, safety, cost-effectiveness, and guidelines. In Human Growth Hormone Treatment for Adult Growth Hormone Deficiency: A Review of the Clinical Effectiveness, Safety, CostEffectiveness, and Guidelines. Ottawa, Canada: Canadian Agency for Drugs and Technologies in Health, 2015.

3 Deijen JB, van Driel MI \& Drent ML. The involvement of the GH/IGF-I axis in cognitive functions of adult patients and healthy subjects. Open Endocrinology Journal 20126 (Supplement 1: M10) 68-79. (doi:10.2174/1874216501206010068)

4 Collett-Solberg PF \& Misra M. The role of recombinant human insulin-like growth factor-I in treating children with short stature. Journal of Clinical Endocrinology and Metabolism 200893 10-18. (doi:10.1210/jc.2007-1534)

5 Kaplan SA \& Cohen P. The somatomedin hypothesis 2007: 50 years later. Journal of Clinical Endocrinology and Metabolism 200792 4529-4535. (doi:10.1210/jc.2007-0526)

6 Pawlikowska-Haddal A. Growth hormone therapy with norditropin (somatropin) in growth hormone deficiency. Expert Opinion on Biological Therapy 201313 927-932. (doi:10.1517/14712598.2013 .795941)

7 Reed ML, Merriam GR \& Kargi AY. Adult growth hormone deficiency - benefits, side effects, and risks of growth hormone replacement. Frontiers in Endocrinology 2013464

8 Guyda HJ. Four decades of growth hormone therapy for short children: what have we achieved? Journal of Clinical Endocrinology and Metabolism 199984 4307-4316. (doi:10.1210/jcem.84.12.6189)

9 Fisher BG \& Acerini CL. Understanding the growth hormone therapy adherence paradigm: a systematic review. Hormone Research in Paediatrics 201379 189-196. (doi:10.1159/000350251)

10 Rosenfeld RG \& Bakker B. Compliance and persistence in pediatric and adult patients receiving growth hormone therapy. Endocrine Practices 200814 143-154. (doi:10.4158/EP.14.2.143)

11 Christiansen JS, Backeljauw PF, Bidlingmaier M, Biller BM, Boguszewski MC, Casanueva FF, Chanson P, Chatelain P, Choong CS, Clemmons DR, et al. Growth Hormone Research Society perspective on the development of long-acting growth hormone preparations. European Journal of Endocrinology 2016174 C1-C8. (doi:10.1530/EJE-16-0111)

12 Cutfield WS, Derraik JG, Gunn AJ, Reid K, Delany T, Robinson E \& Hofman PL. Non-compliance with growth hormone treatment in children is common and impairs linear growth. PLOS ONE 20116 e16223. (doi:10.1371/journal.pone.0016223)

13 Cawley P, Wilkinson I \& Ross RJ. Developing long-acting growth hormone formulations. Clinical Endocrinology 201379 305-309. (doi:10.1111/cen.12240)

14 Laursen T, Gravholt CH, Heickendorff L, Drustrup J, Kappelgaard AM, Jørgensen JO \& Christiansen JS. Long-term effects of continuous

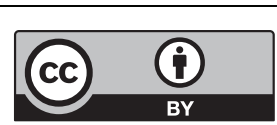

This work is licensed under a Creative Commons Attribution 4.0 International License. 
subcutaneous infusion versus daily subcutaneous injections of growth hormone (GH) on the insulin-like growth factor system, insulin sensitivity, body composition, and bone and lipoprotein metabolism in GH-deficient adults. Journal of Clinical Endocrinology and Metabolism 200186 1222-1228.

15 Jorgensen JO, Møller N, Lauritzen T \& Christiansen JS. Pulsatile versus continuous intravenous administration of growth hormone (GH) in GH-deficient patients: effects on circulating insulinlike growth factor-I and metabolic indices. Journal of Clinical Endocrinology and Metabolism 199070 1616-1623. (doi:10.1210/ jcem-70-6-1616)

16 Tauber M, De Bouet Du Portal H, Sallerin-Caute B, Rochiccioli P \& Bastide R. Differential regulation of serum growth hormone (GH)binding protein during continuous infusion versus daily injection of recombinant human GH in GH-deficient children. Journal of Clinical Endocrinology and Metabolism 199376 1135-1139.

17 Lippe B, Frasier SD \& Kaplan SA. Use of growth hormone-gel. Archives of Disease in Childhood 197954 609-613. (doi:10.1136/adc.54.8.609)

18 Reiter EO, Attie KM, Moshang T Jr, Silverman BL, Kemp SF, Neuwirth RB, Ford KM, Saenger P \& Genentech, Inc.-Alkermes, Inc. Collaborative Study Group. A multicenter study of the efficacy and safety of sustained release GH in the treatment of naive pediatric patients with GH deficiency. Journal of Clinical Endocrinology and Metabolism 200186 4700-4706. (doi:10.1210/jcem.86.10.7932)

19 Food and Drug Administration Division of Drug Marketing Advertising and Communications. Letter to Genentech RE: NDA \#21-075 Nutropin Depot [somatropin (rDNA origin) for injectable supsension] MACMIS ID\# 9082, 28 July 2000. Rockville, MD, USA: Food and Drug Adiminstration, 2000. (available at: http:// wayback.archive-it.org/7993/20170112070554/http:/www.fda.gov/ downloads/Drugs/GuidanceComplianceRegulatoryInformation/ EnforcementActivitiesbyFDA/WarningLettersandNoticeofViolation LetterstoPharmaceuticalCompanies/UCM166042.pdf)

20 Silverman BL, Blethen SL, Reiter EO, Attie KM, Neuwirth RB \& Ford KM. A long-acting human growth hormone (Nutropin Depot): efficacy and safety following two years of treatment in children with growth hormone deficiency. Journal of Pediatric Endocrinology and Metabolism 200215 (Supplement 2) 715-722.

21 Genentech. Nutropin Depot [somatropin (cDNA origin) for injectable suspension]. San Francisco, CA, USA: Genentech Inc, 1999. (available at: https://www.accessdata.fda.gov/drugsatfda_docs/ label/2004/21075s008lbl.pdf)

22 Khadilkar V, Radjuk KA, Bolshova E, Khadgawat R, El Kholy M, Desai M, Peterkova V, Mericq V, Kratzsch J, Siepl EC, et al. 24-month use of once-weekly GH, LB03002, in prepubertal children with GH deficiency. Journal of Clinical Endocrinology and Metabolism 201499 126-132. (doi:10.1210/jc.2013-2502)

23 Roemmler J, Gockel A, Otto B, Bidlingmaier M \& Schopohl J. Effects on metabolic variables after 12-month treatment with a new once-aweek sustained-release recombinant growth hormone (GH: LB03002) in patients with GH deficiency. Clinical Endocrinology 201276 88-95. (doi:10.1111/j.1365-2265.2011.04146.x)

24 Peter F, Bidlingmaier M, Savoy C, Ji HJ \& Saenger PH. Three-year efficacy and safety of LB03002, a once-weekly sustained-release growth hormone $(\mathrm{GH})$ preparation, in prepubertal children with $\mathrm{GH}$ deficiency (GHD). Journal of Clinical Endocrinology and Metabolism 201297 400-407. (doi:10.1210/jc.2011-2234)

25 European Medicines Agency. Assessment report: somatropin biopartners, EMA/CHMP/229458/2013. London, UK: European Medicines Agency, 2013. (available at: http://www.ema.europa.eu/ docs/en_GB/document_library/EPAR_-_Public_assessment_report/ human/002196/WC500148755.pdf)

26 Turecek PL, Bossard MJ, Schoetens F \& Ivens IA. PEGylation of biopharmaceuticals: a review of chemistry and nonclinical safety information of approved drugs. Journal of Pharmaceutical Sciences 2016105 460-475. (doi:10.1016/j.xphs.2015.11.015)

27 Touraine P, D'Souza GA, Kourides I, Abs R, Barclay P, Xie R, Pico A, Torres-Vela E, Ekman B \& GH Lipoatrophy Study Group. Lipoatrophy in GH deficient patients treated with a long-acting pegylated GH. European Journal of Endocrinology 2009161 533-540. (doi:10.1530/ EJE-09-0422)

28 Pfizer Inc. A study to evaluate the dose response and safety of PHA794428 in adults with growth hormone deficiency. New York, NY, USA: Pfizer Inc, 2007. (available at: https://clinicaltrials.gov/ct2/ show/NCT00308464)

29 Sondergaard E, Klose M, Hansen M, Hansen BS, Andersen M, FeldtRasmussen U, Laursen T, Rasmussen MH \& Christiansen JS. Pegylated long-acting human growth hormone possesses a promising once-weekly treatment profile, and multiple dosing is well tolerated in adult patients with growth hormone deficiency. Journal of Clinical Endocrinology and Metabolism 201196 681-688. (doi:10.1210/jc.2010-1931)

30 de Schepper J, Rasmussen MH, Gucev Z, Eliakim A \& Battelino T. Long-acting pegylated human $\mathrm{GH}$ in children with GH deficiency: a single-dose, dose-escalation trial investigating safety, tolerability, pharmacokinetics and pharmacodynamics. European Journal of Endocrinology 2011165 401-409.

31 BioCentury. Clinical results: Novo Nordisk A/S product: NNC1260083. BioCentury 201018 B16-B17.

32 Novo Nordisk A/S. Company announcement - interim financial report for the period 1 January 2010 to 30 September 2010. Bagsværd, Denmark: Novo Nordisk A/S, 2010. (available at: http:// www.novonordisk.com/bin/getPDF.1455626.pdf)

33 European Medicines Agency. Paediatric Committee (PDCO): minutes for the meeting on 24-27 January 2017. London, UK: European Medicines Agency, 2017. (available at: http://www.ema.europa.eu/ docs/en_GB/document_library/Minutes/2017/02/WC500222285.pdf)

34 Racz K, Coculescu M, Olyinik V, Popa M, Popovic V, Radiuk K, Senatorova AS, Vlasenko MV, Norman T, Juhasz M, et al. OR7-6: Safety and efficacy of ARX201: six month dose-ranging study of a novel long-acting pegylated growth hormone in young adults with growth hormone deficiency. Presented at the 7th International Congress of the GRS and the IGF Society, October 17-20 2014, Singapore. Growth Hormone \& IGF Research 201424 (Supplement 1) S20. (doi:10.1016/S1096-6374(14)50052-4)

35 Ivens IA, Achanzar W, Baumann A, Brändli-Baiocco A, Cavagnaro J, Dempster M, Depelchin BO, Rovira AR, Dill-Morton L, Lane JH, et al. PEGylated biopharmaceuticals: current experience and considerations for nonclinical development. Toxicologic Pathology 201543 959-983. (doi:10.1177/0192623315591171)

36 European Medicines Agency. CHMP Safety Working Party's response to the PDCO regarding the use of PEGylated drug products in the paediatric population. London, UK: European Medicines Agency, 2012. (available from: http://www.ema.europa.eu/docs/en_GB/ document_library/Scientific_guideline/2012/11/WC500135123.pdf)

37 Teva Pharmaceutical Industries Ltd. A phase 2, randomized, openlabel, safety and dose-finding study comparing 3 different doses of weekly TV-1106 and daily recombinant human growth hormone (Genotropin) therapy in treatment-naive, pre-pubertal, growth hormone-deficient children. EudraCT number 2013-004468-69. Petach Tikva, Israel: Teva Pharmaceutical Industries Ltd, 2016. (available at: https://www.clinicaltrialsregister.eu/ctr-search/ trial/2013-004468-69/results)

38 Moore WV, Nguyen HJ, Kletter GB, Miller BS, Rogers D, Ng D, Moore JA, Humphriss E, Cleland JL \& Bright GM. A randomized safety and efficacy study of somavaratan (VRS-317), a long-acting rhGH, in pediatric growth hormone deficiency. Journal of Clinical Endocrinology and Metabolism 2016101 1091-1097. (doi:10.1210/ jc.2015-3279) http://www.endocrineconnections.org DOI: 10.1530/EC-17-0203
() 2017 The authors Published by Bioscientifica Ltd

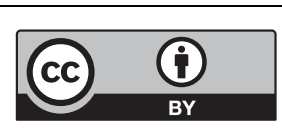

This work is licensed under a Creative Commons Attribution 4.0 International License. 
39 Versartis Inc. Form 10-Q. Commission file number: 001-36361. Washington, DC, USA: United States Securities and Exchange Commission, 2017. (available from: https://www.sec.gov/Archives/ edgar/data/1513818/000156459017010114/vsar-10q_20170331.htm)

40 Thomson Reuters. Edited transcript: VSAR - Versartis Inc at Morgan Stanley Global Healthcare Conference, 18 September 2015. New York, NY, USA: Thomson Reuters, 2015.

41 Zelinska N, Iotova V, Skorodok J, Malievsky O, Peterkova V, Samsonova L, Rosenfeld RG, Zadik Z, Jaron-Mendelson M, Koren R, et al. Long-acting C-terminal peptide-modified hGH (MOD-4023): results of a safety and dose-finding study in GHD children. Journal of Clinical Endocrinology and Metabolism 2017102 1578-1587. (doi:10.1210/jc.2016-3547)

42 OPKO Health Inc. OPKO Health provides update on hGH-CTP clinical programs. Miami, FL, USA: OPKO Health Inc, 2016. (available at: http://investor.opko.com/releasedetail.cfm?ReleaseID=1005839)

43 OPKO Health Inc. OPKO - diagnostics \& pharmaceuticals for large markets with unmet needs. In Presented at JP Morgan 35th Annual Healthcare Conference, 9-12 January 2017, San Francisco, CA, USA Miami, FL, USA: OPKO Health Inc, 2017.

44 Rasmussen MH, Olsen MW, Alifrangis L, Klim S \& Suntum M. A reversible albumin-binding growth hormone derivative is well tolerated and possesses a potential once-weekly treatment profile. Journal of Clinical Endocrinology and Metabolism 201499 E1819-E1829. (doi:10.1210/jc.2014-1702)

45 Thygsen P, Konradsen G \& Nielsen P. Somapacitan (NNC0195 0092) a novel long acting human GH derivative binds tightly, but reversibly to albumin in plasma. Presentation SAT034. Presented at ENDO2016, April 1-4 2016, Boston, MA. Washington, DC, USA Endocrine Society, 2016. (available at: http://www.endocrine.org/ meetings/endo-annual-meetings/abstract-details?ID=27415)

46 Johannsson G, Feldt-Rasmussen U, Haakonsson IH, Bieringd H, Rodiene P, Taharaf S, Toogood A \& Højby M. P1-P594: Somapacitan, A once-weekly reversible albumin-binding growth hormone (GH) derivative, is well tolerated and convenient in adults with GH deficiency: results from a 26-week randomised, controlled phase 3 trial. Presented at ESPE 2016, 10-12 September 2016, Paris, France. Hormone Research in Paediatrics 201686 (Suppl 1) 362. (doi:10.1159/000449142)

47 EU Clinical Trials Register. EudraCT number: 2015-001939-21. London, UK: European Medicines Agency, 2015. (available at: https:// www.clinicaltrialsregister.eu/ctr-search/trial/2015-001939-21/HU)

48 Cittadini A, Berggren A, Longobardi S, Ehrnborg C, Napoli R, Rosén T, Fazio S, Caidahl K, Bengtsson BA \& Saccà L. Supraphysiological doses of GH induce rapid changes in cardiac morphology and function. Journal of Clinical Endocrinology and Metabolism 200287 1654-1659. (doi:10.1210/jcem.87.4.8363)

49 Colao A, Vitale G, Pivonello R, Ciccarelli A, Di Somma C \& Lombardi G. The heart: an end-organ of GH action. European Journal of Endocrinology 2004151 (Supplement 1) S93-S101. (doi:10.1530/ eje.0.151S093)

50 Isgaard J, Arcopinto M, Karason K \& Cittadini A. GH and the cardiovascular system: an update on a topic at heart. Endocrine 2015 48 25-35. (doi:10.1007/s12020-014-0327-6)

51 Pereira AM, van Thiel SW, Lindner JR, Roelfsema F, van der Wall EE, Morreau H, Smit JW, Romijn JA \& Bax JJ. Increased prevalence of regurgitant valvular heart disease in acromegaly. Journal of Clinical Endocrinology and Metabolism 200489 71-75. (doi:10.1210/jc.2003030849)

52 Melmed S. Acromegaly pathogenesis and treatment. Journal of Clinical Investigation 2009119 3189-3202. (doi:10.1172/JCI39375)

53 Farnum CE, Lenox M, Zipfel W, Horton W \& Williams R. In vivo delivery of fluoresceinated dextrans to the murine growth plate: imaging of three vascular routes by multiphoton microscopy.
Anatomical Record Part A: Discoveries in Molecular, Cellular, and Evolutionary Biology 2006288 91-103. (doi:10.1002/ar.a.20272)

54 Gill KL, Gardner I, Li L \& Jamei M. A bottom-up whole-body physiologically based pharmacokinetic model to mechanistically predict tissue distribution and the rate of subcutaneous absorption of therapeutic proteins. AAPS Journal 201618 156-170. (doi:10.1208/ s12248-015-9819-4)

55 Caliceti P. Pharmacokinetics of pegylated interferons: what is misleading? Digestive and Liver Disease 200436 (Supplement 3) S334-S339. (doi:10.1016/S1590-8658(04)80002-1)

56 Watahiki M, Yamamoto M, Yamakawa M, Tanaka M \& Nakashima K. Conserved and unique amino acid residues in the domains of the growth hormones. Flounder growth hormone deduced from the cDNA sequence has the minimal size in the growth hormone prolactin gene family. Journal of Biological Chemistry 1989264 312-326.

57 Moore MC, Smith MS, Sinha VP, Beals JM, Michael MD, Jacober S \& Cherrington AD. Novel PEGylated basal insulin LY2605541 has a preferential hepatic effect on glucose metabolism. Diabetes 201463 494-504. (doi:10.2337/db13-0826)

58 Guevara-Aguirre J, Rosenbloom AL, Vasconez O, Martinez V, Gargosky SE, Allen L \& Rosenfeld RG. Two-year treatment of growth hormone $(\mathrm{GH})$ receptor deficiency with recombinant insulin-like growth factor I in 22 children: comparison of two dosage levels and to GH-treated GH deficiency. Journal of Clinical Endocrinology and Metabolism 199782 629-633.

59 Rosenbloom AL. Insulin-like growth factor-I (rhIGF-I) therapy of short stature. Journal of Pediatric Endocrinology and Metabolism 2008 21 301-315.

60 Chernausek SD, Backeljauw PF, Frane J, Kuntze J, Underwood LE \& GH Insensitivity Syndrome Collaborative Group. Long-term treatment with recombinant insulin-like growth factor (IGF)-I in children with severe IGF-I deficiency due to growth hormone insensitivity. Journal of Clinical Endocrinology and Metabolism 200792 902-910. (doi:10.1210/jc.2006-1610)

61 LeRoith D \& Yakar S. Mechanisms of disease: metabolic effects of growth hormone and insulin-like growth factor 1. Nature Clinical Practice Endocrinology and Metabolism 20073 302-310 (doi:10.1038/ ncpendmet0427)

62 Ross JL, Lee PA, Gut R \& Germak J. Attaining genetic height potential: Analysis of height outcomes from the ANSWER Program in children treated with growth hormone over 5 years. Growth Hormone and IGF Research 201525 286-293. (doi:10.1016/j. ghir.2015.08.006)

63 Laron Z, Ginsberg S, Lilos P, Arbiv M \& Vaisman N. Long-term IGF-I treatment of children with Laron syndrome increases adiposity. Growth Hormone and IGF Research 2006 16 61-64. (doi:10.1016/j. ghir.2005.12.001)

64 Strasburger CJ, Vanuga P, Payer J, Pfeifer M, Popovic V, Bajnok L, Góth M, Olšovská V, Trejbalová L, Vadasz J, et al. MOD-4023, a longacting carboxy-terminal peptide-modified human growth hormone: results of a Phase 2 study in growth hormone-deficient adults. European Journal of Endocrinology, 2017176 283-294. (doi:10.1530/EJE-16-0748)

65 Teva Pharmaceutical Industries Ltd. A 64 week (12 week core phase and 52 week safety extension), phase II, multicenter, randomized, open label study to evaluate the safety, tolerability and efficacy of weekly TV1106 in adults with growth hormone deficiency. EudraCT number 2012-004975-37. Petach Tikva, Israel: Teva Pharmaceutical Industries Ltd, 2016. (available at: https://www.clinicaltrialsregister. eu/ctr-search/trial/2012-004975-37/results)

66 Kang J, Kim P, Kwak EH, Xu M-Y, Han O, Kim Y, Jung SY, Kwon S, Huh Y \& Chapel S. 6 month results of a phase II, randomized, active controlled, open label study of safety and efficacy of HM10560A a long acting r-Hgh-HMC001 conjugate in adult patients with growth hormone deficiency (AGHD). Presentation FRI-447. Presented at (c) 2017 The authors Published by Bioscientifica Ltd

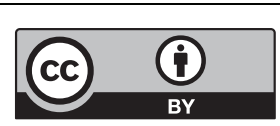

This work is licensed under a Creative Commons Attribution 4.0 International License. 
ENDO2015, March 5-8 2015, San Diego, CA. Washington, DC, USA: Endocrine Society, 2015. (available at: http://press.endocrine.org/doi/ abs/10.1210/endo-meetings.2015.NP.5.FRI-447)

67 Hoybye C, Cohen P, Hoffman AR, Ross R, Biller BM, Christiansen JS \& Growth Hormone Research Society. Status of long-acting-growth hormone preparations - 2015. Growth Hormone and IGF Research 2015 25 201-206. (doi:10.1016/j.ghir.2015.07.004)

68 Yamaoka T, Tabata Y \& Ikada Y. Distribution and tissue uptake of poly(ethylene glycol) with different molecular weights after intravenous administration to mice. Journal of Pharmaceutical Sciences 199483 601-606. (doi:10.1002/jps.2600830432)
69 Chatelain P, Malievskiy O, Radziuk K, Senatorova G, Abdou MO, Vlachopapadopoulou E, Skorodok Y, Peterkova V, Leff JA, Beckert M, et al. A randomized phase 2 study of long-acting TransCon GH vs daily GH in childhood GH deficiency. Journal of Clinical Endocrinology and Metabolism 2017102 1673-1682. (doi:10.1210/ jc.2016-3776)

70 Hoybye C, Pfeiffer AF, Ferone D, Christiansen JS, Gilfoyle D, Christoffersen ED, Mortensen E, Leff JA \& Beckert M. A phase 2 trial of long-acting TransCon growth hormone in adult GH deficiency. Endocrine Connections 20176 129-138. (doi:10.1530/ EC-17-0007)

Received in final form 18 September 2017

Accepted 25 September 2017

Accepted Preprint published online 25 September 2017
C 2017 The authors Published by Bioscientifica Ltd

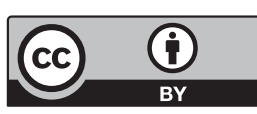

This work is licensed under a Creative Commons Attribution 4.0 International License. 